\title{
THE WEB OF THINGS AND DATABASE MANAGEMENT SYSTEMS \\ ${ }^{1}$ J. Simon, ${ }^{2} Z$. Čović, ${ }^{3}$ D. Dobrilović \\ ${ }^{1}$ Subotica Tech, Department of Informatics, Marka Oreškovića 16, 2400, Subotica, Serbia e-mail:simon@vts.su.ac.rs \\ ${ }^{2}$ Subotica Tech, Department of Informatics, Marka Oreškovića 16, 2400, Subotica, Serbia, e-mail: chole@vts.su.ac.rs \\ ${ }^{3}$ University of Novi Sad / Technical Faculty “Mihajlo Pupin”, Đure Đakovića bb, 23000, Zrenjanin, Serbia, e-mail: ddobrilo@tfzr.rs
}

\begin{abstract}
The Web of Things (WoT) is slowly gaining grounds and through the properties of barcodes, QR codes, RFID, active sensors and IPv6, objects are fitted with some form of readability and traceability. People are becoming part of digital global network driven by personal interests. The feeling being part of a community and the constant drive of getting connected from real life finds it continuation in digital networks. This paper investigates the concepts of the internet of things from the aspect of the autonomous mobile robots with an overview of the performances of the currently available database management systems.
\end{abstract}

Keywords: DBMS performance, Cloud computing, IoT, Web 2.0, Wireless sensor networks

\section{INTRODUCTION}

Information and communication technology has started on large computers called the main frame of the 1960s, the 1970s minicomputer was a practical solution, workstation appeared with the development of the microprocessor in the 1980s, and personal computers became popular in the 1990s. This progress is largely accelerated due to the development of a semi-conductor integrated circuit technology [1]. As a result, the computer and the network cost, made a remarkable progress in terms of performance, have infiltrated and became embedded into the society at large scale. In a network, stemming from the Internet to research of ARPANET, by the 1990s WWW (World Wide Web), showed the explosive spread. In the background, it may become capable of high-speed large-capacity communication by development of optical communication technology. From the wireless communication technology, to the spread of mobile phones and high-speed wireless LAN, all the equipment leads to the era of the global network [25],[26],[28],[28]. Dramatic improvement in communication speed, and to underpin the transition from e-mail to the video content, the fusion of communication and broadcasting has begun and started an expansion of the IoT devices as shown in Fig. 1.

\section{WEB OF THINGS}

The Web of Things is not a single standalone technology, it's a concept in which most new things are connected and enabled such as street lights being networked and things like embedded sensors, image recognition functionality, augmented reality, near field communication are integrated into situational decision support, asset management and new services [2]. These bring many business opportunities and add to the complexity of IT. 


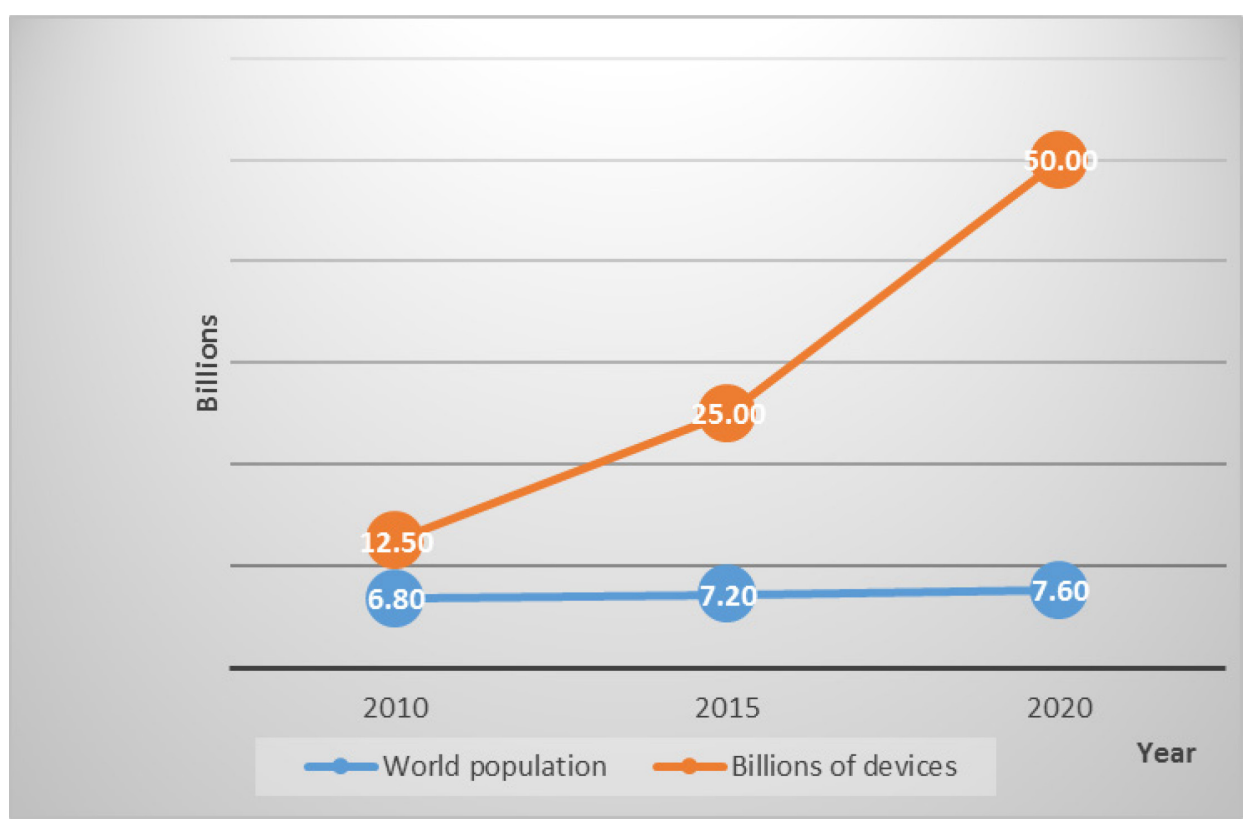

Figure 1. IoT devices and the future evolution

The Web of Things offers solutions based on the integration of information technology, which refers to hardware and software used to store, retrieve, and process data and communications technology which comprises electronic systems used for communication between individuals or groups [3]. The rapid convergence of information and communications technology is occurring at many layers of technology innovation (Fig. 2): the cloud, data and communication pipes/networks and device.
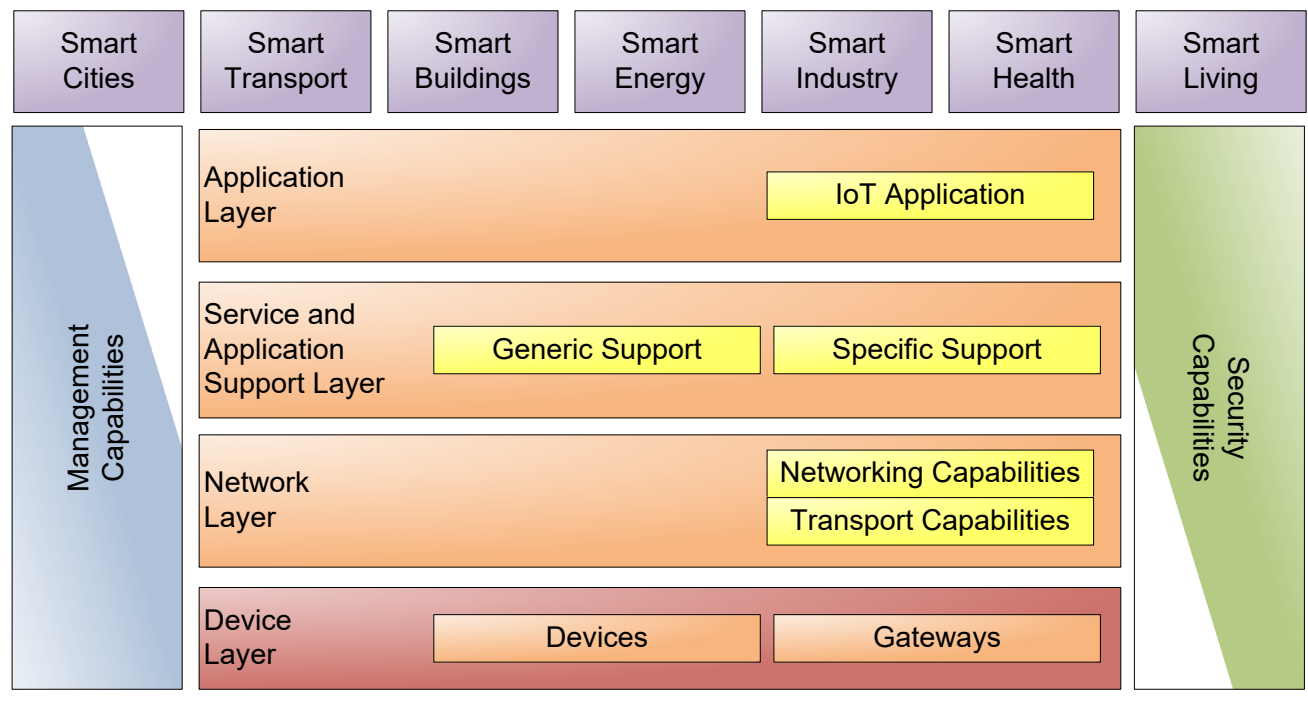

Figure 2. IoT Layered Architecture

The potential market for wireless communication technology is one of the rapidly-spreading segments in the industry of integrated circuits. Rapidly fast innovation, fast changes in communications standards, the 
entry of new players, and the evolution of new market sub segments will lead to disruptions (disorder, confusion) across the industry [4].

\section{IOT AND AUTONOMOUS MOBILE DEVICES}

The connection of vehicles or mobile robots to the Internet brings about a wealth of new possibilities and applications which bring new functionalities to the individuals and/or the making of transport easier and safer. In this context the concept of Internet of Vehicles (IoV) connected with the concept of Internet of Energy (IoE) represent future trends for smart transportation and mobility applications as depicted (described, shown, illustrated) on Fig 3 [5].

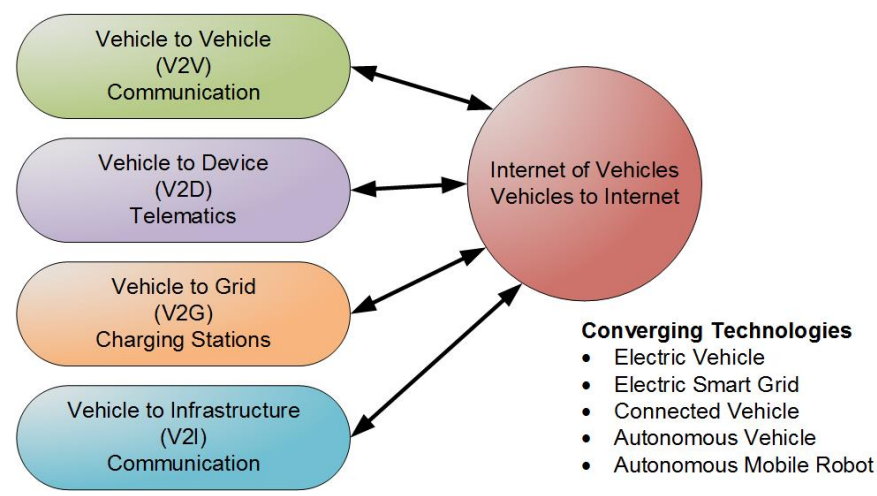

Figure 3. Converging Technologies

Self-driving vehicles today are in the prototype phase and the idea is becoming just another technology on the computing industry's parts list. Using automotive vision chips that can be used to help vehicles understand the environment around them by detecting pedestrians, traffic lights, collisions, drowsy drivers, and road lane markings [6]. Those tasks initially are more the sort of thing that would help a driver in unusual circumstances rather than take over full time.

\section{CONTROL DATA STORAGE TO THE CLOUD}

By its name, a cloud database is a database that runs on a cloud computing platform, such as MS Onedrive, Dropbox and Google Drive. The cloud platform can provide databases as a specialized service, or provide virtual machines to deploy any databases on. Cloud databases could be either relational or non-relational databases. Compared to local databases, cloud databases guarantee higher scalability as well as availability and stability [12],[19],[20],[21]. Thanks to the elasticity of cloud computing, hardware and software resources can be added to and removed from the cloud without much effort. Users only need to pay for the consumed resource while the expenses for physical servers, networking equipment, infrastructure maintenance and administration are shared among clients, thus reducing the overall cost. Additionally, database service is normally provided along with automated features such as backup and recovery, failover, on-the-go scaling, and load balancing.

Cloud computing has been established as one of the major building blocks of the Internet of Things [13]. New technology enablers have progressively fostered virtualization at different levels and have allowed the various paradigms known as "Applications as a Service", "Platforms as a Service" and "Infrastructure and Networks as a Service". As part of this convergence, IoT applications such as sensor-based services will be delivered on-demand through a cloud environment. This extends beyond the need to virtualize sensor data stores in a scalable fashion. It asks for virtualization of Internet-connected objects and their ability to 
become incorporated into on-demand services such as Sensing-as-a-Service. Fig. 4 shows the performances of tested database management systems.

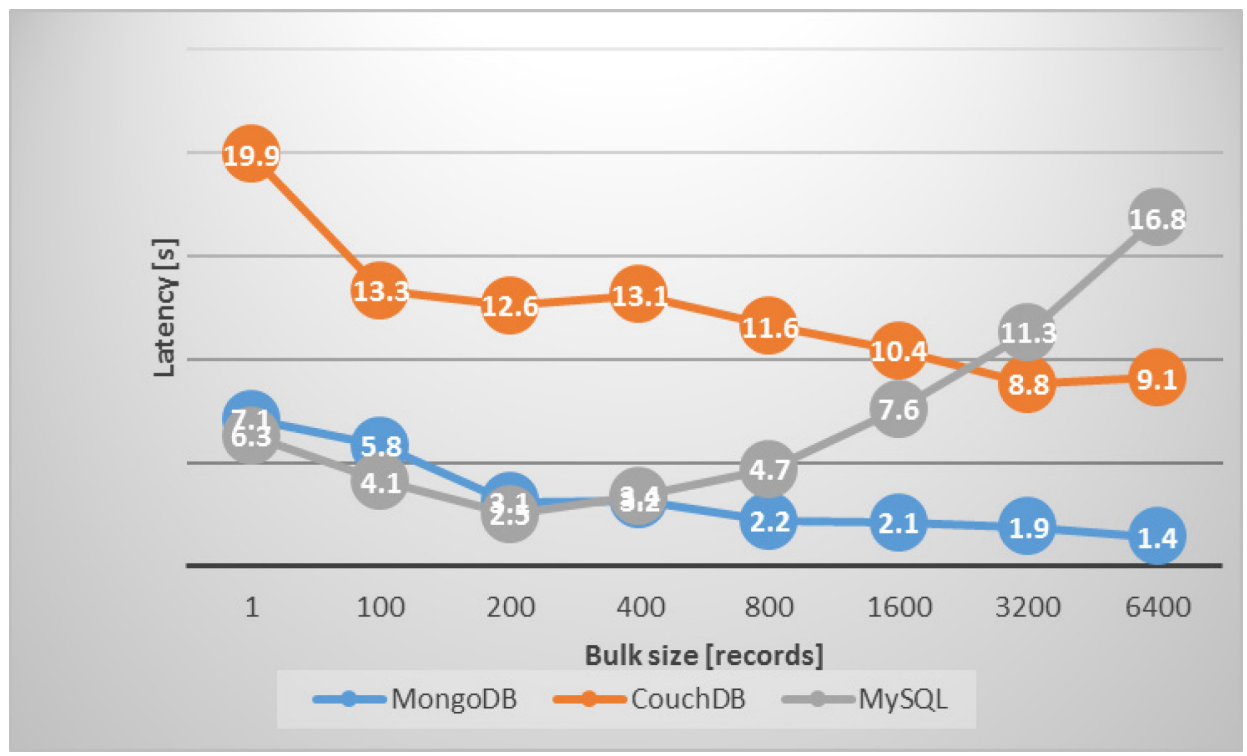

Figure 4. Bulk insert latency test with various DBMS

The choice of the databases was based on the fact that those were among the most popular databases available, and that they were the representatives for their kinds. Many large organizations have been using them in production, such as Facebook, Google, Wikipedia, LinkedIn, Instagram, etc. On the other hand, each database has its own promising strength that is worth exploring. MySQL so far has been the most popular open source SQL database. MongoDB was built to work with very large sets of data [13],[14],[18],[22]. CouchDB has its user-friendly RESTful API. Meanwhile, Redis is said to be very fast thanks to its in-memory storage. Redis is an open source, BSD licensed, advanced key-value cache and store system. With the bulk data, the MongoDB has the smallest latency, but the overall best score goes to MySQL.

Other important issues considering the Web of Things and Database services are system parameters such as Bit Error Rate (BER) and Packet Error Rate (PER). The PER values presented in this research are percentages calculated as a ratio of number of packets with errors divided with the total number of packets sent. Presented results are made during the two separate experiments using Arduino UNO platform and two different communication modules using ZigBee technology in indoor environment. The presented values are illustrative and not comparable because they are not used in the same experimental conditions. More data about the experiment can be found in [23],[24].

In experiment No. 1 [23] from each position ZigBee node sent 2500 packet in $100 \mathrm{~ms}$ interval. The duration of data transmission and the distance of the measurement stations from coordinator are given in Tab. 1. 
Table 1. Results Concerning Packet Statistics Experiment No. 1

\begin{tabular}{|c|c|c|c|}
\hline Position & $\begin{array}{c}\text { Packets Sent } \\
\text { (No.) }\end{array}$ & $\begin{array}{c}\text { Distance } \\
(\boldsymbol{m})\end{array}$ & $\begin{array}{c}\text { PER } \\
(\%)\end{array}$ \\
\hline 1 & 10087 & 1 & 0.73 \\
\hline 2 & 10865 & 10 & 1.51 \\
\hline 3 & 10091 & 6.5 & 0.66 \\
\hline 4 & 10153 & 18 & 1.82 \\
\hline 5 & 10126 & 12.5 & 0.41 \\
\hline 6 & 10231 & 26.5 & 1.29 \\
\hline 7 & 10171 & 31.5 & 1.7 \\
\hline
\end{tabular}

In experiment No. 2 [24] data are sent as ASCII bytes. The packets are encrypted which results together with payload with 81 Bytes long packet. The data are sent every $100 \mathrm{~ms}$. Very short inter packet interval in both case is defined for the experimental purposes in order to analyse frequent packet transmission which are common for the presented environments.

Table 2. Results Concerning Packet Statistics Experiment No. 2

\begin{tabular}{|c|c|c|c|c|c|c|}
\hline Loc. & $\begin{array}{l}\text { Packet } \\
\text { Sent }\end{array}$ & $\begin{array}{l}\text { Data Packets } \\
\text { Sent }\end{array}$ & Errors & PER (\%) & Dist. (m) & Floor \\
\hline 1 & $457 \mathrm{~d} 8$ & 4507 & 22 & 0.48 & 1 & $1^{\text {st }}$ \\
\hline 2 & 4520 & 4395 & 44 & 0.97 & 18 & $1^{\text {st }}$ \\
\hline 3 & 4553 & 4356 & 62 & 1.36 & 26.5 & $1^{\text {st }}$ \\
\hline 4 & 4328 & 4049 & 114 & 2.63 & 28 & $1^{\text {st }}$ \\
\hline 5 & 1292 & 669 & 287 & 22.21 & 31.5 & $1^{\text {st }}$ \\
\hline 6 & 3067 & 2729 & 100 & 3.26 & 30.2 & $1^{\text {st }}$ \\
\hline 7 & 3080 & 2777 & 111 & 3.6 & 29 & $1^{\text {st }}$ \\
\hline 8 & 3032 & 2733 & 117 & 3.86 & 25.5 & $1^{\text {st }}$ \\
\hline 9 & 2880 & 2321 & 267 & 9.27 & 22.5 & $1^{\text {st }}$ \\
\hline 10 & 2821 & 1625 & 546 & 19.35 & 16 & $2^{\text {nd }}$ \\
\hline 11 & 9 & 0 & 0 & 0 & 19.5 & $2^{\text {nd }}$ \\
\hline 12 & 1693 & 796 & 407 & 24.04 & 17 & $2^{\text {nd }}$ \\
\hline 13 & 2435 & 1473 & 484 & 19.88 & 9.5 & $2^{\text {nd }}$ \\
\hline 14 & 3181 & 3104 & 22 & 0.69 & 9 & $2^{\text {nd }}$ \\
\hline
\end{tabular}

\section{WEB 2.0 ENVIRONMENT}

A Web 2.0 site may allow users to interact and collaborate with each other in a social media dialogue as creators of user-generated content in a virtual community, in contrast to Web sites where people are limited to the passive viewing of content. Examples of Web 2.0 include social networking sites, blogs, wikis, folksonomies, video sharing sites, hosted services, Web applications, and mashups.

Rapid Web Development means quick and efficient web application building. It is part of the Rapid Software Development described in [15],[29],[31],[32]. Besides the obvious objective of meeting customers' deadline, another characteristic of Rapid Web Development is fast prototyping. Mockups and partial web application versions aid evaluation, usability testing and simulation of planned features.

The Rapid Web Development process uses existing technologies and brings them together allowing us to focus on the real task of application building. It implies integration of readily available open source and free to use software, frameworks, APIs, libraries, data sources, external services and functionality to create a platform for running our Web 2.0 service. This development model is known as "Mashup" - a web application hybrid [16],[30]. 
Fig. 5 illustrates a simple mashup model where web services and multiple external and internal data sources are combined.

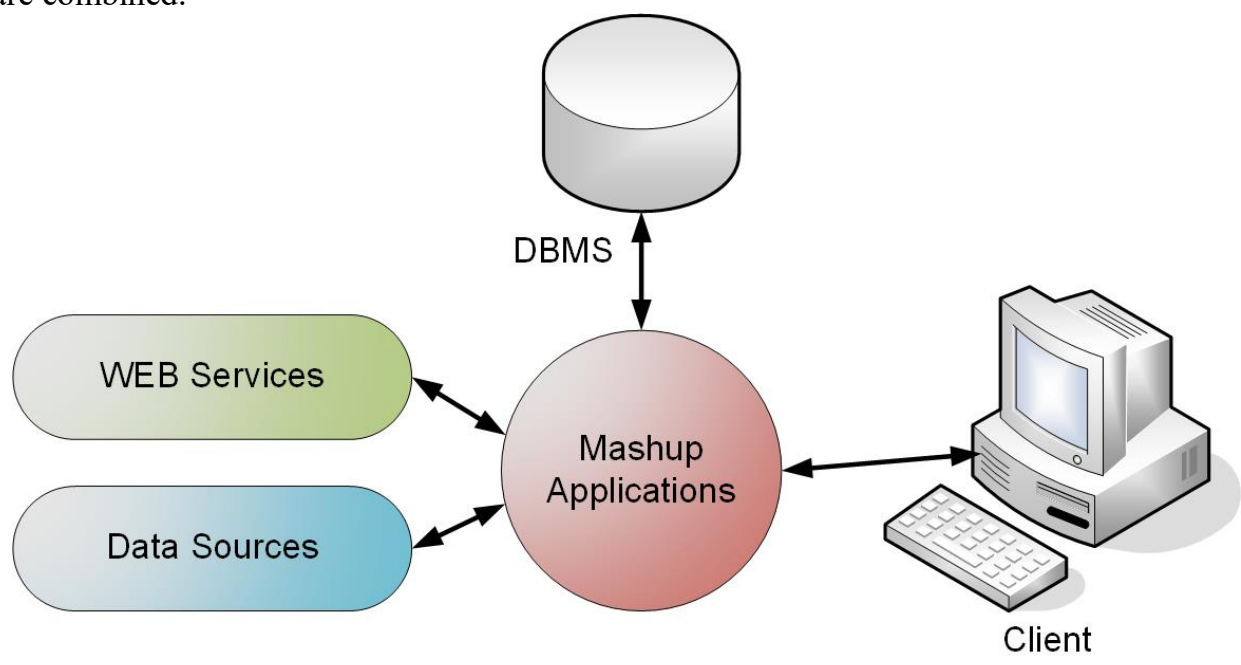

Figure 5. Mashup model illustration

The term mashup originally comes from British - West Indies slang meaning to be intoxicated, or as a description for something or someone not functioning as intended. In recent English parlance it can refer to music, where people seamlessly combine audio from one song with the vocal track from another-thereby mashing them together to create something new.

\section{CONCLUSION}

The concept of Internet of Vehicles (IoV) is the next step for future smart transportation and mobility applications and requires creating new mobile ecosystems based on trust, security and convenience to mobile/contactless services and transportation applications in order to ensure security, mobility and convenience to consumer-centric transactions and services. This requires robust sensors and actuators which are able to reliably deliver information to the systems mentioned above. Such reliable communication needs to be based on M2M communication protocols which consider the timing, safety, and security constraints.

The vision of the future Internet of Things is setting new challenges and opportunities for data management and analysis technology. Gigabytes of data are generated everyday by millions of sensors, actuators, RFID tags, and other devices. As the volume of data is growing dramatically, so is the demand for performance enhancement. When it comes to this Big Data problem, much attention has been paid to cloud computing and virtualization for their unlimited resource capacity, flexible resource allocation and management, and distributed processing ability that promise high scalability and availability.

\section{REFERENCES}

[1] M. Arndt, S. Wille, L. De Souza, V. Fortes Rey, N. Wehn and K. Berns, "Performance evaluation of ambient services by combining robotic frameworks and a smart environment platform", Robotics and Autonomous Systems, 61 (11), (2013), pp. 1173-1185.

[2] L. Atzori, A. Iera, G. Morabito and M. Nitti, "The Social Internet of Things (SIoT) - When social networks meet the Internet of Things: Concept, architecture and network characterization", Computer Networks, 56 (16), (2012), pp. 3594-3608. 
[3] E. Borgia, "The Internet of Things vision: Key features, applications and open issues", Computer Communications, 54, (2014), pp. 1-31.

[4] S. H. Chiu, P. L. Urban, "Robotics-assisted mass spectrometry assay platform enabled by open-source electronics", Biosensors and Bioelectronics, 64, (2015), pp. 260-268.

[5] S. Distefanoa, G. Merlinoc and A. Puliafitoc, "A utility paradigm for IoT: The sensing Cloud", Pervasive and Mobile Computing, 17 (1), (2014), pp. 1-39.

[6] L. A. Griecoa, A. Rizzoa, S. Coluccia, S. Sicaric, G. Piroa, D. Di Paolab and G. Boggiaa, "IoT-aided robotics applications: Technological implications, target domains and open issues", Computer Communications, 54 (1), (2014), pp. 32-47.

[7] J. Gubbia, R. Buyyab, S. Marusica, and M. Palaniswamia, "Internet of Things (IoT): A vision, architectural elements, and future directions", Future Generation Computer Systems, 29 (7), (2013), pp. $1645-1660$.

[8] G. Martinović, J. Simon and I. Matijevics, "Greenhouse Microclimatic Environment Controlled by a Mobile Measuring Station", Journal of the Royal Netherlands Society for Agricultural Sciences, 70 (1), (2014), pp. 61-70.

[9] Gy. Mester, "Improving the Mobile Robot Control in Unknown Environments", Proceedings of the YUINFO'2007, Kopaonik, Serbia, 11-14.03.2007, pp. 1-5.

[10] Gy. Mester, "Distance Learning in Robotics", Proceedings of The Third International Conference on Informatics, Educational Technology and New Media in Education, Sombor, Serbia 2006, pp. 239245.

[11] J. Simon, "Optimal Microclimatic Control Strategy Using Wireless Sensor Network and Mobile Robot", Acta Agriculturae Serbica, 18 (36), (2013), pp. 3-12.

[12] J. Simon and G. Martinovic, "Navigation of Mobile Robots Using WSN's RSSI Parameter and Potential Field Method", Acta Polytechnica Hungarica, 10(4), (2013), pp. 107-118.

[13] J. Simon and I. Matijevics, "Simulation and Implementation of Mobile Measuring Robot Navigation Algorithms in Controlled Microclimatic Environment Using WSN", Proceedings of the IEEE 9th International Symposium on Intelligent Systems and Informatics - SISY 2011, Subotica, 2011, pp. 275-279.

[14] S. Vijaykumar and S. G. Saravanakumar, "Future Robotics Database Management System Along With Cloud TPS", International Journal on Cloud Computing: Services and Architecture, 1(3), (2011), pp. 103-114.

[15] F. Rousseaux and K. Lhoste, "Rapid Software Prototyping Using Ajax and Google Map API", International Conference on Advances in Computer-Human Interaction, (2009), pp. 317-323.

[16] Mashups: The next major new software development model, [Online]. Available: http://blogs.zdnet.com/Hinchcliffe/?p=106 [Last accessed: July 2016].

[17] D. Dobrilović, Z. Čović, Ž. Stojanov and V. Brtka, “Approach In Teaching Wireless Sensor Networks and IoT Enabling Technologies In Undergraduate University Courses", Proceedings of the 2nd regional conference Mechatronics in Practice and Education, MechEdu (2013), pp. 18-22.

[18] Internet of Things [Online]. Available: http://www.intel.com/content/www/us/en/internet-ofthings/overview.html [Last accessed: July 2016].

[19] I. Matijevics, J. Simon, „Advantages of Remote Greenhouse Laboratory for Distant Monitoring”, Proceedings of the Conference ICoSTAF (2008), pp. 1-5.

[20] J. Simon, G. Martinović, "Web Based Distant Monitoring and Control for Greenhouse Systems Using the Sun SPOT Modules", Proceedings of the Conference SISY (2009), pp. 1-5.

[21] B. Kuljić, J..Simon, T. Szakáll, „Mobile robot controlled by voice”, Proceedings of the Conference SISY 2007, Subotica, Serbia, 2007, pp. 189-192.

[22] J. Simon, Z. Covic, "Data Management of the Automomous Mobile Devices and Internet of Things", ANNALS of Faculty Engineering Hunedoara - International Journal of Engineering, 13 (3), (2015), pp. 265-268. 
[23] D. Dobrilovic, Z. Stojanov, V. Brtka, Z. Čović, N. Bilinac, "Software Application for Analyzing ZigBee Network Performance in University Courses, unpublished, submitted to the IEEE 12th International Symposium on Intelligent Systems and Informatics in June 2014.

[24] D. Dobrilovic, B. Odadzic, Z. Stojanov, V. Sinik, „Testing Zigbee RF module applicability for usage in temperature monitoring systems", Proceeding of 22nd Telecommunications Forum Telfor (TELFOR), (2014), pp. 415-418.

[25] Z. Gál, B. Almási, T. Dabóczi, R. Vida, S. Oniga, S. Baran, I. Farkas, "Internet of Things: Application Areas and Research Results of the FIRST Project", Infocommunications Journal, 6 (3), (2014), pp. 37-44.

[26] Gy. Terdik, Z. Gal, "Advances and practice in Internet of Things: A case study", Proceedings of IEEE 4th International Conference on Cognitive Infocommunications (CogInfoCom 2013), (2013), pp. 435440.

[27] J. Sárosi, I. Bíró, J. Németh, L. Cveticanin, "Dynamic Modelling of a Pneumatic Muscle Actuator with Two-direction Motion", Mechanism and Machine Theory, 85, (2015), pp. 25-34.

[28] Z. Nyikes, Z. Rajnai, "The Big Data and the relationship of the Hungarian National Digital Infrastructure", International Conference on Applied Internet and Information Technologies, ICAIIT (2015), pp. 6-12.

[29] Á. Bálint, J. Sárosi, "The Design and Implementation of a Radio Controlled Led Lighting System", Analecta Technica Szegedinensia, 10 (1), (2016), pp. 29-34.

[30] S. Csikós, "Robot Remote Control over the Internet", 28th International Conference Science in Practice, (2010), pp. 41-43.

[31] J. Simon, Z. Cović, I. Fürstner, L. Gogolak, D. Dobrilović, "The Web of Things and Database Services", Proceedings of the International conference on Applied Internet and Information Technologies AIIT (2015), pp. 235-238.

[32] J. Sárosi (2014): "Measurement and Data Acquisition”, University of Szeged, Faculty of Engineering, Szeged, $100 \mathrm{p}$. 